See discussions, stats, and author profiles for this publication at: https://www.researchgate.net/publication/321718840

\title{
Inclusion and affective wellbeing: Roles of justice perceptions
}

Article in Personnel Review · December 2017

DOI: 10.1108/PR-03-2017-0078

CITATIONS

0

4 authors:

Huong Le

Deakin University

47 PUBLICATIONS $\mathbf{8 1}$ CITATIONS

SEE PROFILE

0

Yuka Fujimoto

Sunway Education Group

58 PUBLICATIONS $\mathbf{3 4 8}$ CITATIONS

SEE PROFILE

\section{READS}

70

Zhou Jiang

Deakin University

33 PUBLICATIONS 151 CITATIONS

SEE PROFILE

Ingrid Nielsen

Deakin University

91 PUBLICATIONS 895 CITATIONS

SEE PROFILE

Some of the authors of this publication are also working on these related projects:

Project Social inclusion and cultural engagement View project

Project Inclusive business and Innovation View project 


\section{Inclusion and affective wellbeing: Roles of justice perceptions}

Le, Huong, Jiang, Zhou, Fujimoto, Yuka, and Nielsen, Ingrid

Deakin University, Australia

This paper has been accepted by Personnel Review in 2017.

\section{To cite this paper:}

Le, Huong, Jiang, Zhou, Fujimoto, Yuka and Nielsen, Ingrid. (in press). Inclusion and affective wellbeing: Roles of justice perceptions. Personnel Review. 


\title{
Inclusion and affective wellbeing: roles of justice perceptions
}

\begin{abstract}
Purpose - This paper examines the mediating roles of procedural justice and distributive justice in the organizational inclusion-affective wellbeing relationship.

Design/methodology/approach - Data were collected from 253 Australian employees using an online survey. The study used confirmatory factor analysis and structural equation modeling to analyze the data.

Findings - Organizational inclusion was positively related to both distributive justice and procedural justice. The relationship between organizational inclusion and affective wellbeing was mediated by both distributive justice and procedural justice.

Research limitations/implications - The cross-sectional design may have limited the empirical inferences; however, the proposed model was based on robust theoretical contentions, thus mitigating the limitation of the design. Data were collected from a single organization, thus limiting generalizability.

Practical implications - Implementation of inclusion training activities at organizational, group, and individual levels is important to enhance perceptions of organizational inclusion and subsequently improve employee affective wellbeing.

Originality/value - Based on the group engagement model and group-value model of justice, this paper adds to the literature by demonstrating two mediating mechanisms driving the organizational inclusion-affective wellbeing relationship.
\end{abstract}


Keywords Organizational inclusion, Procedural justice, Distributive justice, Wellbeing.

\section{Introduction}

Based upon the group engagement model (Tyler and Blader, 2003) and group-value model of justice (Lind and Tyler, 1988; Tyler and Lind, 1992), this study examines the relationship between organizational inclusion and affective wellbeing. Creating inclusive climates is critical to the workplace given its relationship with employee wellbeing. We argue that such an inclusive climate enhances affective wellbeing because it can lead employees to perceive fairness in the organization. Organizational inclusion denotes the degree to which employees feel "a part of critical organizational processes such as access to information and resources, involvement in work groups, and ability to influence the decision-making process" (Mor Barak and Cherin, 1998, p. 48). Inclusion is also about having a voice (Sabharwal, 2014), belongingness (Shore et al., 2011; van Prooijen et al., 2004), and the individual feeling of being accepted and valued in the workplace (Pelled et al., 1999; Roberson, 2006). It is often viewed from a workplace environment perspective (Fujimoto et al., 2014), which suggests that inclusive work environments may drive employees' perceptions about the organization and thus influence their affective states (Leary and Downs, 1995).

Although Findler et al. (2007) found that workplace inclusion tends to increase employees' wellbeing, their focus was on general wellbeing (depression and strain) and stress (role conflict, role âmbiguity, and role overload) that mix psychological or affective aspects with physical health, and therefore do not enable a clear understanding of the unique contribution of inclusion to the affective component of wellbeing. This paper advances this area by specifically focusing on affective wellbeing (i.e., a worker's positive psychological state of mind). This is not only due to the lack of empirical evidence on affective wellbeing but also because it is a critical 
factor that helps reduce negative work attitudes such as job dissatisfaction (Colquitt et al., 2001) and turnover intentions (Simons and Roberson, 2003), and prevent negative work behaviors such as absenteeism and poor performance (e.g., Ybema and van den Bos, 2010).

Building on previous studies that have shown that inclusion can positively affect wellbeing (Greenhaus et al., 1990; Mor Barak et al., 1998), the present study models two mediating mechanisms proposed to drive the influence of inclusion on wellbeing. Prior literature suggests that when employees feel that they are included in important workplace activities or processes, they are likely to perceive fairness (Findler et al., 2007), which facilitates the development of wellbeing (e.g., Elovainio et al., 2005; Lawson et al., 2009; Le et al., 2016; Ybema and van den Bos, 2010). According to the group engagement model, which is an expansion of the group-value model of justice (Lind and Tyler, 1988), the perceived fairness resulting from inclusive climates can shape employees' social identity and cooperation in the organization and foster their positive state of mind (Tyler and Blader, 2003). Consistent with this perspective, we argue that justice perceptions mediate the relationship between organizational inclusion and affective wellbeing. Among the three dimensions (distributive, procedural, and interactional) of organizational justice, procedural and distributive justice are particularly relevant to organization-oriented variables, whereas interactional justice (both interpersonal and informational components) is more relevant to variables related or specific to supervisors (Cropanzano et al., 2002; Jiang et al., 2016). Because organizational inclusion is an organization-oriented variable that is referenced to the organization or system as a whole, we focus only on the mediating roles of distributive and procedural justice.

This paper has novel contributions to the literature in two aspects. First, the current study identifies a new antecedent (i.e., organizational inclusion) of employee affective wellbeing. 
Despite a variety of factors that have been theorized to influence affective wellbeing, empirical studies are still yet to demonstrate specifically whether organizational inclusion can improve affective wellbeing. This examination is particularly critical for the workplace because it will advance and strengthen our understanding of how important inclusion is for both the employee and the organization, and thus prompt employers to revisit their inclusion policies and practices (Shore et al., 2011). Second, this study extends justice theories such as the group engagement theory (Tyler and Blader, 2003) and the group-value model of justice (Lind and Tyler, 1988), by establishing the justice-based mechanisms underlying the inclusion-wellbeing relationship. Stepping beyond prior studies that focus on the simple interrelations between inclusion- and wellbeing-related variables (e.g., Correa-Velez et al., 2010), these mediation mechanisms expand our theoretical and empirical insights regarding why inclusive climates can benefit employees' affective wellbeing. In this way, the current study also sheds light on future research that is required to further understand additional mediation processes that transmit the effects of inclusion to employee wellbeing.

\section{Literature review and hypotheses development}

\subsection{Organizational inclusion, and justice perceptions}

Organizational inclusion, which highlights the inclusive decision-making process, is a critical factor that contributes to employees' sense of shared identity, positive social interactions, and cooperation amongst employees with diverse backgrounds (Shore et al., 2011). The key benefits of inclusion for individuals include higher levels of employee wellbeing and productivity, job satisfaction, and lower levels of turnover and absenteeism. These benefits can also be extended to the organizational level in the form of profits and performance (Sabharwal, 2014). This study 
examines how perceived organizational inclusion contributes to affective wellbeing, arguing that organizational inclusion influences affective wellbeing because it can influence employees' relational perceptions regarding organizational processes (i.e., procedural justice) and outcomes (distributive justice). The following section discusses the relationships between organizational inclusion and justice perceptions, and then theorizes the relationships between justice perceptions and affective wellbeing.

Procedural justice refers to perceived fairness about processes, including decision-making processes and having voice in those processes, which are used to determine employees' work outcomes, such as promotions and pay (Greenberg, 2004). Distributive justice refers to perceived fairness of employees' decision outcomes, which result from these processes, in relation to their work contributions (Adams, 1965; Cropanzano et al., 2002). According to the group-value model (or relational model of authority) (Lind and Tyler, 1988) and group engagement model (Tyler and Blader, 2003), group membership is essential as people have strong needs of belonging, security, and socialization (Tyler, 1989; Tyler et al., 1996). In alignment with the perspective of the need to belong (Baumeister and Leary, 1995), these two models focus on the extent to which people are treated well in groups. The assumption of both models is that members of a group can judge whether they are respected and valued in their group, and based on this judgment, they exhibit positive or negative attitudes toward their group (i.e., organizations) and develop varying degrees of shared social identity with their group. For example, applying the group-value model to workplace justice phenomena, Tyler (1989) implies that fair procedures are usually perceived as symbolic messages of group inclusion, whereas unfair procedures tend to be perceived as symbolic messages of being excluded from, or rejected by, a group. This implication suggests that inclusion in a group shapes a group member's perception of procedural justice. Considering 
that it has been shown that procedural justice is likely to be accompanied by distributive justice (although the reverse might not be always be the case [McFarlin and Sweeney, 1992]), it is logical to expect that inclusion in a group should increase the likelihood that employees perceive distributive justice.

These theoretical perspectives generated from the group-value model and group engagement model have obtained some initial empirical support. For instance, Findler et al. (2007) found that workplace inclusion can increase the overall fairness perceived by organizational members. Unfortunately, their research did not provide clear information regarding how fairness was defined and measured, nor did it examine justice at the dimensional level (e.g., distributive and procedural justice). However, Wenzel's (2000) study has, to some extent, complemented Findler et al.'s findings, implying that inclusion is important in promoting employees’ justice motives (e.g., distributive and procedural justice). Although Wenzel operationalized inclusion based on social categorization in a broader context, the similar connotation that underlies the various conceptualizations of inclusion makes it feasible to extend the study implications to organizational settings. Despite the lack of direct empirical evidence, the above theoretical arguments and empirical evidence indicate that the levels of perceived or experienced inclusion should contribute to employees’ perceptions of procedural and distributive justice. Taken together, the study proposes the following hypothesis:

H1. Organizational inclusion is positively related to distributive justice (H1a) and procedural justice $(H 1 b)$.

\subsection{Justice perceptions and affective wellbeing}

As discussed, the theoretical perspective of the group-value or relational model (Tyler, 1989; Tyler et al., 1996; Tyler and Lind, 1992) can help to explain how justice perceptions build upon 
inclusion practices. The literature suggests that the group-value model can also extend to explaining the influence of justice perceptions on employee outcomes (e.g., affective wellbeing). The group-value model proposes that procedural justice has important effects on an individual's psychological state, attitudes, and behaviors in a group, as it to some extent reflects the quality of people’s social connection with their group members and group authorities (Tyler et al., 1996). That is, fair treatment or reward recognition by authorities or senior managers signifies that individuals are respected and valued within their group. The feelings of pride and respect in a group as a consequence of fair treatment may lead to employees' group-serving behaviors or attitudes, which are likely reflections and products of their positive psychological states (e.g., affective wellbeing and work satisfaction) (Farh et al., 1990).

The above viewpoint is supported by Martin and Bennett's (1996) insights that distributive and procedural justice perceptions are sources of satisfaction at work, which can lead to employee positive attitudinal outcomes (e.g., commitment to the group or organization) that benefit groups and reflect employees' feeling of being valued in their group. These views suggest that if a group (or its representatives) and its policies and practices are characterized as positive and just, it is likely that individuals will perceive their work situations and conditions to be enjoyable, which leads to a sense of belonging, attachment, and comfort in the group or organization. Such individual psychological processes and feelings initiated by fair and favorable treatment are, in turn, likely to foster employees’ psychological wellbeing (Haslam et al., 2009). These theoretical bases suggest that perceptions of organizational justice may shape employee affective wellbeing.

Past research has provided empirical evidence to support the association between procedural justice and psychological wellbeing (Elovainio et al., 2005; Judge and Colquitt, 2004; 
Kausto et al., 2005; Le et al., 2016; Tepper, 2001). For example, Ybema and van den Bos (2010) found that employees who perceived procedural injustice reported more depressive symptoms than those who did not. Qin et al. (2014) found that procedural unfairness can negatively affect employees’ psychological wellbeing. Considering procedural justice as a type of social support or a means of social integration of employees within a group (Elovainio et al., 2001), prior studies also found that when employees perceive organizational processes as fairer, they tend to have a greater sense of social support, experience less stress in work roles, and report a higher level of wellbeing (Findler et al., 2007; Le et al., 2016).

The association between distributive justice and employee psychological wellbeing has also been documented in empirical research. The findings vary in the literature. Although a few studies have found that distributive justice had no effect on employee wellbeing (e.g., Moliner et al., 2008; Rodwell et al., 2011), much research supports a positive (or negative) relationship between distributive justice (or injustice) and wellbeing. The overall conclusion that can be drawn from the latter stream of research is that those who report low levels of distributive justice often experience low levels of wellbeing (de Boer et al., 2002; Le et al., 2016; Tepper, 2001). For example, Judge and Colquitt (2004) found that distributive justice can shape employees' affective states that are related to psychological wellbeing (e.g., increased job satisfaction, decreased perception of work-family conflict), despite the lack of support for their proposition regarding the distributive justice-stress relationship. From the perspective of equity theory, Adam (1965) and Greenberg (1990) theorized that employees feel dissatisfied with job outcomes if they perceive that their outcomes are less than their expectation or less than the reward of their referents. Building on this contention, Greenberg (2004) argued that perceptions of distributive unfairness can lead to poor employee affective wellbeing or various deviant behaviors. Tepper 
(2001) and Greenberg (2004) affirmed that distributive injustice, like procedural injustice, can be linked to various stress-related issues. Taken together, we propose:

H2. Distributive justice (H2a) and procedural justice $(H 2 b)$ are positively related to affective wellbeing.

H3. The relationship between organizational inclusion and affective wellbeing is mediated by distributive justice $(H 3 a)$ and procedural justice $(H 3 b)$.

\section{Methods}

\subsection{Sample and procedure}

Data were collected through a 20-minute online survey. An email invitation containing a hyperlink to the online survey was sent to employees, and a follow-up email was sent two weeks later. Prospective participants were assured that participation was voluntary and anonymous and that results would only be published in aggregate. The purpose of the study was described as "to capture a clearer understanding of the justice perceptions held by employees at the university, and to generate diversity initiatives to enhance the fairness of the university's diversity practices, policies and work relationships.” Before the launch of the main survey, a pilot study was conducted to test content validity of the items with 60 randomly selected full-time employees in the higher education industry in Australia.

The final sample consisted of 253 usable responses, representing a valid response rate of $16 \%$. The gender distribution of the respondents was $37.5 \%$ male and $62.5 \%$ female. Age had the following distributions: 3.6\% below 25 years, $26.9 \%$ between 25 and 39, $45.5 \%$ between 40 and 54, 23.7\% between 55 and 70, and $0.4 \%$ above 70 . Most of the survey participants (77.9\%) had permanent employment status. Organizational tenure had the following distribution: $12.3 \%$ had 
been employed for less than one year, 38.3\% for between one and five years, $20.9 \%$ for between six and 10 years, and $28.5 \%$ for more than 10 years. Sixty-eight percent were in a non-academic role. Seventy-six percent held a full-time position.

\subsection{Measures}

\subsubsection{Organizational inclusion}

The three-item instrument developed by Bortree and Waters (2008) was employed to measure organizational inclusion. Participants responded to a five-point Likert scale $(1=$ strongly disagree and 5 = strongly agree). A sample item was "I am usually invited to important meetings in my organization.” The Cronbach’s alpha for this measure was 0.67.

\subsubsection{Procedural and distributive justice}

Colquitt's (2001) seven-item measure was employed to assess employees' perceptions of procedural justice. Participants responded on a five-point Likert scale ranging from " 1 = to a small extent" to " 5 = to a large extent." A sample item was "Have you been able to express your views and feelings during those procedures?” Participants were advised that the "procedures" in these items referred to the procedures used to arrive at their outcomes. The Cronbach's alpha for this measure was 0.86 .

Distributive justice was measured by the four-item scale developed by Colquitt (2001). In the study, the term "outcomes" is defined as work outcomes, such as rewards, promotions and performance appraisal ratings. Sample items are "Is your (outcome) appropriate for the work you have completed?" and "Does your (outcome) reflect what you have contributed to the organization?” The Cronbach’s alpha for distributive justice was 0.93. 


\subsubsection{Affective wellbeing}

The study measured affective wellbeing using the six-item scale developed by Warr (1990). Respondents were asked to rate six wellbeing states described as "tense," "uneasy," "worried," "calm," "contented," and "relaxed." A sample item is "Thinking of the past few weeks, how much of the time has your job made you feel each of the following?" Responses ranged from 1 (never) to 5 (all of the time). Responses to the first three items were reverse-coded. The Cronbach’s alpha for this six-item scale was 0.92 .

\subsubsection{Control variables}

The study controlled for the demographic characteristics of the respondents, namely age, gender, employment status, organizational tenure, cultural identity, and disability.

\subsection{Data analysis}

Anderson and Gerbing's two-step procedure, which involves confirmatory factor analysis (CFA) and structural equation modeling (SEM), was employed to analyze the data. SEM was employed because it has been more effective than traditional regression analyses in capturing interrelationships among latent variables (Schreiber et al., 2006). For example, it allows researchers to specify and test the path model of latent constructs as well as the measurement model that denotes the relationships between latent variables and their observed indicators (Kline, 2015). In particular, scholars contend that SEM is better suited for testing models with two or more mediators, such as the current model that contains two mediators: distributive justice and procedural justice) (LeBreton et al., 2009). Prior to hypothesis testing, a series of CFAs was performed to test the discriminant validity of the four variables (i.e., organizational inclusion, distributive justice, procedural justice, and affective wellbeing). Then, two sets of 
SEMs were performed and compared to identify the best structural model based on the hypotheses.

For the CFA and SEM used in the current study, the item parceling strategy recommended by predecessors (e.g., Little et al., 2002; Nasser-Abu Alhija and Wisenbaker, 2006) for those variables measured with four or more items was used. This approach has been employed and proved reliable in numerous studies (Chen et al., 2005; Jiang, 2016; Jiang et al., 2017). An advantage of item parceling is that it can reduce the number of indicators for latent variables, and thus reduce the potential inflated measurement errors caused by too many indicators on a single latent variable (Nasser-Abu Alhija and Wisenbaker, 2006). Adopting the item-to-construct balance approach (Little et al., 2002), items with the highest and lowest loadings were bundled successively until every item was assigned to a parcel. The mean score of the items within the same parcel was used as the score for the parcel indicator. Three item parcels were finally created for distributive justice, procedural justice, and affective wellbeing.

The following indexes were used to evaluate model fit: the ratio of chi-square to the degree of freedom $\left(\chi^{2} / d f\right)$, which is less influenced by sample size relative to chi-square $\left(\chi^{2}\right)$ (Jöreskog and Sörbom, 1996); the standardized root mean residual (SRMR); the root mean square error approximation (RMSEA); and the comparative fit index (CFI). As per prior research (Kline, 2015), for adequate model fit, $\chi^{2} / d f$ should be smaller than 5.0, SRMR and RMSEA should be smaller than or close to 0.08 , and CFI should be over 0.90 .

\section{Results}

To test the measurement model, the baseline model (four-factor) was compared with several competing models, which were composited in line with the underlying conceptual foundation. The literature suggests that individuals may occasionally mix the feelings of different types of 
justice, and in certain cases the perceived inclusion may not be rationally distinguished from justice perceptions (Wayne et al., 2002). For these reasons, it is important to ensure these concepts or constructs are empirically distinct. Accordingly, the three-factor model was set up by combining any two of the three constructs (distributive justice, procedural justice, and organizational inclusion) and the two-factor model by combining distributive and procedural justice. The CFA results (see Table 1) demonstrated that the hypothesized four-factor model was preferred based on the fit indexes outlined above.

INSERT TABLE 1 HERE

Since all data were collected from a single source (e.g., self-reported by respondents), common method bias (CMB) was also checked. First, the most frequently used Harman's onefactor test was employed to examine the potential bias (Podsakoff et al., 2003). The CFA results showed that the four-factor model fit the data much better than the one-factor model (see the fit indexes in Table 1). Second, the study conducted CFA for a four-factor model with a latent method factor added, which is considered a stronger and more rigorous procedure to test CMB (MacKenzie and Podsakoff, 2012; Podsakoff et al., 2003). In this model, all parcel indicators were loaded on their own factors as well as the method factor. Results showed that this model fit the data slightly better than the four-factor model (see Table 1). However, the model improvement was negligible. For example, CFI was nearly the same for both models and the CFI difference (0.003) was far from the cut-off value of 0.05. Thus, CMB was not a significant issue in this study.

These results suggested that the study variables, namely, organizational inclusion, distributive justice, procedural justice, and affective wellbeing, could be empirically 
distinguished from one another. Therefore, it would be appropriate to treat them as separate variables or constructs in subsequent analyses. The means, standard deviations, and correlations of variables are shown in Table 2.

\section{INSERT TABLE 2 HERE}

SEM in AMOS 23.0 was conducted to test the hypotheses. Compared with traditional correlation and regression analyses, SEM performs better, since latent variables are constructed based on multiple items that measure the same construct, and in this way, the construct is defined with only common variance and free of measurement errors (Engle, 2002). Two structural models (i.e., the partial and full mediation models) were compared to identify the best fitting model. As shown in Table 3, although SRMR, RMSEA, and CFI were almost the same for both models, the value of $\chi^{2} / d f$ was smaller for the full mediation model $\left(\chi^{2} / d f=1.39\right)$ than for the partial mediation model $\left(\chi^{2} / d f=1.40\right)$. Given the high similarity of these indexes across the two models, further comparisons were carried out employing Akaike information criterion (AIC) (Akaike, 1987) and the expected cross-validation index (ECVI) (Browne and Cudeck, 1993). A model with smaller values of AIC and ECVI is considered to fit the data better (Blunch, 2008). As demonstrated in Table 3, the AIC (283.11 vs 284.00) and ECVI (1.12 vs 1.13) values were smaller for the full mediation model. Further, it was found that in the partial mediation model, the estimate for the direct path from organizational inclusion to affective wellbeing was not significant $(\beta=0.11, \mathrm{p}=0.29)$. Taking into account these results, the full mediation model was selected as the final structural model. 
The standardized estimates for the final model are displayed in Figure 1. After demographics were controlled, organizational inclusion was found to positively and significantly affect both distributive justice $(\beta=0.59, \mathrm{p}<0.001)$ and procedural justice $(\beta=0.66, \mathrm{p}<0.001)$, supporting $H 1 a$ and $H 1 b$. When demographics and organizational inclusion were controlled, both distributive justice $(\beta=0.35, \mathrm{p}<0.001)$ and procedural justice $(\beta=0.22, \mathrm{p}<0.001)$ were significantly and positively related to affective wellbeing. Thus, $H 2 a$ and $H 2 b$ were supported.

INSERT FIGURE 1 HERE

In light of the methodology for testing mediating effects (Hayes, 2009), the support of $H 1$ and $\mathrm{H} 2$ provided initial signs for the mediation roles of distributive justice and procedural justice. The study further used the PROCESS macro code (Hayes, 2013) to calculate the unstandardized indirect effects and their corresponding bias-corrected confidence interval (CI) (5,000 bootstrap samples). The indirect or mediating effect is significant when the bootstrapbased CI does not include zero (Hayes, 2013; Preacher et al., 2007). Results showed that the indirect effect of organizational inclusion on affective wellbeing via distributive justice was significant $(\mathrm{b}=0.18, \mathrm{SE}=0.05,95 \% \mathrm{CI}=[0.09,0.29])$, as was the indirect effect via procedural justice $(\mathrm{b}=0.11, \mathrm{SE}=0.05,95 \% \mathrm{CI}=[0.02,0.22])$. Therefore, $H 3 a$ and $H 3 b$ were supported. The comparison of these two indirect effects did not show a significance difference $(\Delta b=0.07$, $\mathrm{SE}=0.08,95 \% \mathrm{CI}=[-0.09,0.24])$, indicating that distributive justice and procedural justice played comparably strong mediating roles in the relationship between organizational inclusion and affective wellbeing. 


\section{Discussion and implications}

This study examined the relationship between organizational inclusion and affective wellbeing and the mediating role of procedural and distributive justice. Results indicated that organizational inclusion is positively related to procedural and distributive justice and that the relationship between organizational inclusion and affective wellbeing is mediated by procedural and distributive justice. These findings have important theoretical implications.

The study has added to the inclusion literature by confirming the role of organizational inclusion in contributing to employees' affective wellbeing. Extending the group-value model (Tyler, 1989; Tyler et al., 1996), the results illustrate how employees' perceptions of being included in a group and being treated with respect and dignity by group members and group authorities positively influence their affective wellbeing. Specifically, the findings show that distributive justice and procedural justice transmit the influence of organizational inclusion to affective wellbeing, offering an explanation for the process through which inclusion might assist in improving wellbeing.

These results support the theoretical perspective of the group-value model (Tyler, 1989; Tyler et al., 1996), which highlights the important role of group effects on individuals in organizational settings. The results suggest that organizational practices that symbolize inclusion of group members send out the message that members are valued, and this symbolic information leads employees to feel respected and well treated, which in turn makes them judge inclusion practices as fair and favorable. The findings are in line with those of Haslam et al. (2009), highlighting that when the group provides individuals with meaningful direction and support, this can lead to improvements in their affective wellbeing. 
Additionally, this study has provided support for equity theory (Adams, 1965; Greenberg, 1990) by testing how distributive justice perceptions are formed and how they exert influences on individual outcomes (i.e., affective wellbeing). As discussed above, justice perceptions serve as mediators linking inclusion and wellbeing. The results in relation to distributive justice indicate that organizational inclusion practices may be able to reduce members' negative reactions to their feelings of inequity when comparing their own with others' work outcomes, and further maintain affective wellbeing. To a certain degree, these findings have extended both theoretical perspectives (i.e., the group-value model and equity theory) by empirically indicating two paths that link organizational inclusion to affective wellbeing.

The study provides important practical implications for managers in maximizing the effects of inclusion on the workforce. To facilitate inclusion in the workplace, organizations and managers will benefit from creating inclusive environments that allow all employees, regardless of their differences (e.g., in age, gender, ethnicity, and job positions), to work well together and participate in decision-making processes that affect their work outcomes. Sabharwal's (2014) findings show that productive workplaces are ones where employees are encouraged to voice their views and where their views are sought before important organizational decisions are made. Shore et al. (2011) proposed a model of the antecedents and consequences of inclusion that include various contextual factors contributing to inclusion in organizations. Specifically, the findings, along with those generated from past research, have provided informed evidence that guides management practices. First, developing an inclusive work context is important at the organizational level. Diversity researchers have argued that organizational diversity initiatives are most effective if managers can address the sources of inequality (DiTomaso et al., 2007). Justice pertaining to fair procedures, distributions of outcomes, and treatment among group 
members is particularly relevant to inclusion (Shore et al., 2011). For example, managers may create an inclusive climate by actively seeking advice and suggestions from minority members through promoting their equal opportunity to speak up in meetings, or to provide de-identified feedback on workplace issues. Top management can also deliberately enhance the representative participation across hierarchy, roles, and social groups to enhance employees’ perceptions of procedural and distributive justice (Fujimoto and Härtel, 2017). To ensure managerial effectiveness in these processes, diversity and inclusion policies and practices should be in place so that all employees can be encouraged and incentivized to be involved in decision-making processes that directly affect their job content, outcomes, or working environments (Sabharwal, 2014).

Second, for the inclusive organizational decision-making process to take place, managers should be educated about the importance of organizational inclusiveness through various channels such as CEO talks, company newsletters, flyers and websites. There is empirical evidence of the importance of the values and philosophy of top management in relation to diversity and equal employment opportunity (Avery et al., 2007), which can then facilitate inclusion in organizations. When managers value inclusiveness, organizations may benefit from employees' positive judgments and reactions that are particularly related to organizational decision-making processes. Indeed, the group-value model (Tyler et al., 1996) and group engagement model (Tyler and Blader, 2003) both suggest that fair treatment from organizational managers who endorse inclusion and diversity conveys a message that employees are respected and valued within the organization, and that this message can shape employee wellbeing (i.e., Shore et al., 2011; Tyler et al., 1996). 
Third, as discussed previously, the findings have demonstrated the important roles of inclusion in generating positive employee outcomes. In light of Bortree and Waters' study (2008), as non-discriminative organizational practices to a large extent drive the conceptualization of inclusion, our results further suggest that a discrimination-free environment in the workplace can also facilitate launching and implementing inclusive management practices. For example, group leaders (e.g., department managers) can deliberately create inclusive heterogeneous participation in departmental meetings that actively invite employees to learn about different perspectives and provide suggestions on how the department can function better.

There are several limitations that should be addressed in future research. First, since data were collected from a single university in Australia, the findings may not be generalizable to other types of organizations because of potential differences in organizational culture. However, given that universities tend to have similar cultures, the results may be generalizable to the university sector (Jiang et al., 2016). Future research may endeavor to further understand the mediating role of organizational justice in the influence of inclusion on employee outcomes using employee samples from other types of workplaces. Second, although the hypotheses were grounded in solid theoretical contentions, the cross-sectional data may have limited the causal inferences of the relationships between inclusion, justice perceptions, and affective wellbeing. Future research might consider using a longitudinal or experimental design to provide more robust findings in respect of the causal relationships among these variables. Third, due to the single-source data collected at the same time point, this study may have been affected by CMB. Although the CFA results showed that the CMB might not be a significant issue in this research, this limitation of the study design may mean that the risk of CMB cannot be completely ruled out. Future research may endeavor to collect data from multiple sources, and attempt to compare 
the findings with those that are based solely on self-report data. Finally, the study included only distributive and procedural justice. Although theoretically these two types of justice are more relevant in studying organization-oriented practices (i.e., organizational inclusion), interpersonal and informational justice may nonetheless also be affected by these practices given that authorities often serve as representatives of the organizational system. Future research may examine all types of justice and empirically explore whether organizational inclusion has differential effects on other justice dimensions. 


\section{References}

Adams, J.S. (1965), "Inequity in social exchange", in Berkowitz, L. (Ed.), Advances in Experimental Social Psychology, Academic Press, New York, NY, pp. 267-299.

Akaike, H. (1987), "Factor analysis and AIC", Psychometrika, Vol. 52 No. 3, pp. 317-332.

Avery, D.R., McKay, P.F., Wilson, D. C. and Tonidandel, S. (2007), "Unequal attendance: the relationships between race, organizational diversity cues, and absenteeism", Personnel Psychology, Vol. 60 No. 4, pp. 875-902, doi:10.1111/j.1744-6570.2007.00094.x.

Baumeister, R.F. and Leary, M.R. (1995), "The need to belong: desire for interpersonal attachments as a fundamental human motivation", Psychological Bulletin, Vol. 117 No. 3, pp. 497-529, doi:10.1037/0033-2909.117.3.497.

Blunch, N.J. (2008), Introduction to Structural Equation Modelling Using SPSS and AMOS, Sage, London.

Boardman, J.D. (2004), "Stress and physical health: the role of neighborhoods as mediating and moderating mechanisms", Social Science \& Medicine, Vol. 58 No. 12, pp. 2473-2483, doi: http://dx.doi.org/10.1016/j.socscimed.2003.09.029.

Bortree, D.S. and Waters, R.D. (2008), "The value of feeling included: the impact of inclusion on teen volunteers' organizational satisfaction", International Journal of Volunteer Administration, Vol. 25 No. 1, pp. 27-39.

Browne, M.W. and Cudeck, R. (1993), "Alternative ways of assessing model fit", in Bollen, K.A. and Long, J.S. (Eds.), Testing structural equations models, Sage, Newbury Park, CA, pp. 136-162.

Chen, Z.X., Aryee, S. and Lee, C. (2005), "Test of a mediation model of perceived organizational support", Journal of Vocational Behavior, Vol. 66 No. 3, pp. 457-470, doi: http://dx.doi.org/10.1016/j.jvb.2004.01.001.

Colquitt, J.A. (2001), "On the dimensionality of organizational justice: a construct validation of a measure", Journal of Applied Psychology, Vol. 86 No. 3, pp. 386-400, doi:10.1037/00219010.86.3.386.

Colquitt, J.A., Conlon, D.E., Wesson, M.J., Porter, C.O.L.H. and Ng, K.Y. (2001), "Justice at the millennium: a meta-analytic review of 25 years of organizational justice research", Journal of Applied Psychology, Vol. 86 No. 3, pp. 425-445, doi:10.1037/00219010.86.3.425.

Correa-Velez, I., Gifford, S. M., \& Barnett, A. G. (2010), "Longing to belong: Social inclusion and wellbeing among youth with refugee backgrounds in the first three years in Melbourne, Australia", Social Science \& Medicine, Vol. 71 No. 8, pp. 1399-1408.

Cropanzano, R., Prehar, C.A. and Chen, P.Y. (2002), "Using social exchange theory to distinguish procedural from interactional justice", Group \& Organization Management, Vol. 27 No. 3, pp. 324-351, doi:10.1177/1059601102027003002.

de Boer, E.M., Bakker, A.B., Syroit, J.E. and Schaufeli, W.B. (2002), "Unfairness at work as a predictor of absenteeism", Journal of Organizational Behavior, Vol. 23 No. 2, pp. 181197, doi:10.1002/job.135.

DiTomaso, N., Post, C. and Parks-Yancy, R. (2007), "Workforce diversity and inequality: power, status, and numbers", Annual Review of Sociology, Vol. 33 No. 1, pp. 473-501, doi:10.1146/annurev.soc33.040406.131805. 
Elovainio, M., Kivimäki, M. and Helkama, K. (2001), "Organizational justice evaluations, job control, and occupational strain", Journal of Applied Psychology, Vol. 86 No. 3, pp. 418424, doi:10.1037/0021-9010.86.3.418.

Elovainio, M., van den Bos, K., Linna, A., Kivimäki, M., Ala-Mursula, L., Pentti, J. and Vahtera, J. (2005), "Combined effects of uncertainty and organizational justice on employee health: Testing the uncertainty management model of fairness judgments among Finnish public sector employees", Social Science \& Medicine, Vol. 61 No. 12, pp. 2501-2512, doi:10.1016/j.socscimed.2005.04.046.

Engle, R.W. (2002), "Working memory capacity as executive attention", Current Directions in Psychological Science, Vol. 11 No. 1, pp. 19-23.

Farh, J.-L., Podsakoff, P.M. and Organ, D. W. (1990), "Accounting for organizational citizenship behavior: leader fairness and task scope versus satisfaction", Journal of Management, Vol. 16 No. 4, pp. 705-721, doi:10.1177/014920639001600404.

Findler, L., Wind, L.H. and Mor Barak, M.E. (2007), "The challenge of workforce management in a global society: modeling the relationship between diversity, inclusion, organizational culture, and employee well-being, job satisfaction and organizational commitment", Administration in Social Work, Vol. 31 No. 3, pp. 63-94, doi:10.1300/J147v31n0305.

Fujimoto, Y., Rentschler, R., Le, H., Edwards, D. and Härtel, C.E.J. (2014), "Lessons learned from community organizations: inclusion of people with disabilities and others", British Journal of Management, Vol. 25 No. 3, pp. 518-537, doi:10.1111/1467-8551.12034.

Fujimoto, Y. \& Härtel C. E. J. (in press), "Organizational Diversity Learning Framework: Going Beyond Diversity Training Programs", Personnel Review.

Fujishiro, K. and Heaney, C.A. (2009), "Justice at work, job stress, and employee health", Health Education \& Behavior, Vol. 36 No. 3, pp. 487-504, doi:10.1177/1090198107306435.

Greenberg, J. (1990), "Organizational justice: yesterday, today, and tomorrow", Journal of Management, Vol. 16 No. 2, pp. 399-432, doi:10.1177/014920639001600208.

Greenberg, J. (2004), "Stress fairness to fare no stress: managing workplace stress by promoting organizational justice", Organizational Dynamics, Vol. 33 No. 4, pp. 352-365, doi:10.1016/j.orgdyn.2004.09.003.

Greenhaus, J. H., Parasuraman, S. and Wormley, W. M. (1990), "Effects of race on organizational experiences, job performance evaluations, and career outcomes", Academy of Management Journal, Vol. 33 No. 1, pp. 64-86, doi:10.2307/256352.

Haslam, S.A., Jetten, J., Postmes, T. and Haslam, C. (2009), "Social identity, health and wellbeing: an emerging agenda for applied psychology", Applied Psychology, Vol. 58 No. 1, pp. 1-23, doi:10.1111/j.1464-0597.2008.00379.x.

Hayes, A.F. (2009), "Beyond Baron and Kenny: statistical mediation analysis in the new millennium", Communication Monographs, Vol. 76 No. 4, pp. 408-420.

Hayes, A.F. (2013), Introduction to Mediation, Moderation, and Conditional Process Analysis: A Regression-Based Approach, Guilford, New York, NY

Jiang, Z. (2016), "The relationship between career adaptability and job content plateau: the mediating roles of fit perceptions", Journal of Vocational Behavior, Vol. 95 No., pp. 110.

Jiang, Z., Gollan, P.J. and Brooks, G. (2016), "Relationships between organizational justice, organizational trust and organizational commitment: a cross-cultural study of China, South Korea and Australia", International Journal of Human Resource Management, [online], pp. 1-32, doi:10.1080/09585192.2015.1128457. 
Jiang, Z., Le, H., \& Gollan, P. J. (2017), "Cultural intelligence and voice behavior among migrant workers: the mediating role of leader-member exchange", International Journal of Human Resource Management, [online], pp. 1-31, doi: 10.1080/09585192.2017.1322119.

Jöreskog, K.G. and Sörbom, D. (1996), LISREL 8: User's Reference Guide, Scientific Software International, Chicago, IL.

Judge, T.A. and Colquitt, J.A. (2004), "Organizational justice and stress: the mediating role of work-family conflict", Journal of Applied Psychology, Vol. 89 No. 3, pp. 395-404, doi:10.1037/0021-9010.89.3.395.

Kausto, J., Elo, A.-L., Lipponen, J. and Elovainio, M. (2005), "Moderating effects of job insecurity in the relationships between procedural justice and employee well-being: gender differences", European Journal of Work and Organizational Psychology, Vol. 14 No. 4, pp. 431-452, doi:10.1080/13594320500349813.

Kline, R.B. (2015), Principles and Practice of Structural Equation Modeling, Guilford Press, New York, NY.

Le, H., Zheng, C. and Fujimoto, Y. (2016), "Inclusion, organisational justice and employee wellbeing", International Journal of Manpower, Vol. 37 No. 6, pp. 945-964, doi:10.1108/IJM-12-2015-0212.

Leary, M.R. and Downs, D.L. (1995), "Interpersonal functions of the self-esteem motive", in Kernis, M.H. (Ed.), Efficacy, Agency, and Self-Esteem, Springer US, Boston, MA, pp. 123-144.

LeBreton, J.M., Wu, J. and Bing, M.N. (2009), "The truth(s) on testing for mediation in the social and organizational sciences", in Lance, C.E. and Vandenberg, R.J. (Eds.), Statistical and Methodological Myths and Urban Legends, Routledge, New York, NY, pp. 107-142.

Lind, E. A., \& Tyler, T. R. (1988). The Social Psychology of Procedural Justice, Plenum, New York, NY.

Little, T.D., Cunningham, W.A., Shahar, G. and Widaman, K.F. (2002), "To parcel or not to parcel: exploring the question, weighing the merits", Structural Equation Modeling, Vol. 9 No. 2, pp. 151-173.

MacKenzie, S.B. and Podsakoff, P.M. (2012), "Common method bias in marketing: causes, mechanisms, and procedural remedies", Journal of Retailing, Vol. 88 No. 4, pp. 542-555.

Martin, C.L. and Bennett, N. (1996), "The role of justice judgments in explaining the relationship between job satisfaction and organizational commitment", Group \& Organization Management, Vol. 21 No. 1, pp. 84-104, doi:10.1177/1059601196211005.

McFarlin, D.B. and Sweeney, P.D. (1992), "Distributive and procedural justice as predictors of satisfaction with personal and organizational outcomes", Academy of Management Journal, Vol. 35 No. 3, pp. 626-637, doi:10.2307/256489.

Mor Barak, M.E. and Cherin, D.A. (1998), "A tool to expand organizational understanding of workforce diversity: exploring a measure of inclusion-exclusion", Administration in Social Work, Vol. 22 No. 1, pp. 47-64.

Mor Barak, M.E., Cherin, D.A. and Berkman, S. (1998), "Organizational and personal dimensions in diversity climate: ethnic and gender differences in employee perceptions", Journal of Applied Behavioral Science, Vol. 34 No. 1, pp. 82-104, doi:10.1177/0021886398341006. 
Nasser-Abu Alhija, F. and Wisenbaker, J. (2006), "A Monte Carlo study investigating the impact of item parceling strategies on parameter estimates and their standard errors in CFA", Structural Equation Modeling, Vol. 13 No. 2, pp. 204-228.

Pelled, L.H., Ledford, J.G.E. and Mohrman, S.A. (1999), "Demographic dissimilarity and workplace inclusion", Journal of Management Studies, Vol. 36 No. 7, pp. 1013-1031, doi:10.1111/1467-6486.00168.

Podsakoff, P.M., MacKenzie, S.B., Lee, J.Y. and Podsakoff, N.P. (2003), "Common method biases in behavioral research: a critical review of the literature and recommended remedies", Journal of Applied Psychology, Vol. 88 No. 5, pp. 879-903.

Preacher, K.J., Rucker, D.D. and Hayes, A.F. (2007), "Addressing moderated mediation hypotheses: theory, methods, and prescriptions", Multivariate Behavioral Research, Vol. 42 No. 1, pp. 185-227.

Qin, X., DiRenzo, M.S., Xu, M. and Duan, Y. (2014), "When do emotionally exhausted employees speak up? Exploring the potential curvilinear relationship between emotional exhaustion and voice", Journal of Organizational Behavior, Vol. 35 No. 7, pp. 10181041, doi:10.1002/job.1948.

Roberson, Q.M. (2006), "Disentangling the meanings of diversity and inclusion in organizations", Group \& Organization Management, Vol. 31 No. 2, pp. 212-236, doi:10.1177/1059601104273064.

Sabharwal, M. (2014), "Is diversity management sufficient? Organizational inclusion to further performance", Public Personnel Management, [online], doi:10.1177/0091026014522202.

Schreiber, J.B., Nora, A., Stage, F.K., Barlow, E.A. and King, J. (2006), "Reporting structural equation modeling and confirmatory factor analysis results: a review", Journal of Educational Research, Vol. 99 No.6, pp. 323-338, doi:10.3200/JOER.99.6.323-338.

Shore, L.M., Randel, A.E., Chung, B.G., Dean, M.A., Ehrhart, K.H. and Singh, G. (2011), "Inclusion and diversity in work groups: a review and model for future research", Journal of Management, Vol. 37 No. 4, pp. 1262-1289, doi:10.1177/0149206310385943.

Simons, T. and Roberson, Q. (2003), "Why managers should care about fairness: the effects of aggregate justice perceptions on organizational outcomes", Journal of Applied Psychology, Vol. 88 No. 3, pp. 432-443, doi:10.1037/0021-9010.88.3.432.

Tepper, B.J. (2001), "Health consequences of organizational injustice: tests of main and interactive effects", Organizational Behavior and Human Decision Processes, Vol. 86 No. 2, pp. 197-215, doi:http://dx.doi.org/10.1006/obhd.2001.2951.

Tyler, T.R. (1989), "The psychology of procedural justice: a test of the group-value model", Journal of Personality and Social Psychology, Vol. 57 No. 5, pp. 830, doi:10.1037/00223514.57.5.830.

Tyler, T.R., Degoey, P. and Smith, H. (1996), "Understanding why the justice of group procedures matters: a test of the psychological dynamics of the group-value model", Journal of Personality and Social Psychology, Vol. 70 No. 5, pp. 913-930, doi:10.1037/0022-3514.70.5.913.

Tyler, T.R. and Lind, E.A. (1992), "A relational model of authority in groups", in P. Z. Mark (Ed.), Advances in Experimental Social Psychology, Academic Press, New York, NY, Vol. 25, pp. 115-191.

Tyler and Blader (2003), "The group engagement model: procedural justice, social identity, and cooperative behavior", Personality and Social Psychology Review, Vol. 7 No. 4, pp. 349361. 
van Prooijen, J.-W., van den Bos, K. and Wilke, H.A.M. (2004), "Group belongingness and procedural justice: Social inclusion and exclusion by peers affects the psychology of voice", Journal of personality and social psychology, Vol. 87 No. 1, pp. 66-79, doi:10.1037/0022-3514.87.1.66.

Warr, P. (1990), "The measurement of well- being and other aspects of mental health", Journal of Occupational Psychology, Vol. 63 No. 3, pp. 193-210.

Wayne, S.J., Shore, L.M., Bommer, W.H. and Tetrick, L.E. (2002), "The role of fair treatment and rewards in perceptions of organizational support and leader-member exchange", Journal of Applied Psychology, Vol. 87 No. 3, pp. 590-598, doi:10.1037/00219010.87.3.590.

Wenzel, M. (2000), "Justice and identity: The significance of inclusion for perceptions of entitlement and the justice motive", Personality and Social Psychology Bulletin, Vol. 26 No. 2, pp. 157-176, doi:10.1177/0146167200264004.

Ybema, J.F. and van den Bos, K. (2010), "Effects of organizational justice on depressive symptoms and sickness absence: A longitudinal perspective", Social Science \& Medicine, Vol. 70 No. 10, pp. 1609-1617, doi:10.1016/j.socscimed.2010.01.027. 
Table 1. CFA results for the measurement model

\begin{tabular}{lrrrccc}
\hline \multicolumn{1}{c}{ Models } & \multicolumn{1}{c}{$\chi^{2}$} & \multicolumn{1}{c}{$d f$} & $\chi^{2} / d f$ & SRMR & RMSEA & CFI \\
\hline 1-factor model & 925.15 & 54 & 17.14 & 0.13 & 0.25 & 0.59 \\
2-factor model & 379.77 & 53 & 7.17 & 0.09 & 0.16 & 0.85 \\
3-factor model A & 309.25 & 51 & 6.06 & 0.08 & 0.14 & 0.88 \\
3-factor model B & 170.27 & 51 & 3.34 & 0.07 & 0.10 & 0.94 \\
3-factor model C & 136.81 & 51 & 2.68 & 0.06 & 0.08 & 0.96 \\
4-factor model & 70.00 & 48 & 1.42 & 0.03 & 0.04 & 0.99 \\
4-factor model with & 48.66 & 36 & 1.35 & 0.02 & 0.04 & 0.99 \\
a method factor & & & & & &
\end{tabular}

Note: $\mathrm{N}=253$. 1-factor model: the four variables were loaded on a single factor; 2-factor model: organizational inclusion, distributive justice and procedural justice were loaded on one factor; 3-factor model A: distributive justice and procedural justice were loaded on one factor; 3-factor model B: organizational inclusion and distributive justice were loaded on one factor; 3-factor model C: organizational inclusion and procedural justice were loaded on one factor; 4-factor model: all four variables were treated as independent factors; 4-factor model with a method factor: all four variables were treated as independent factors, with all indicators also being loaded on the method factor. 
Table 2. Means, standard deviations, and correlations

\begin{tabular}{|c|c|c|c|c|c|c|c|c|c|c|c|}
\hline Variables & $\mathrm{M}$ & SD & 1 & 2 & 3 & 4 & 5 & 6 & 7 & 8 & 9 \\
\hline 1. Gender & 0.38 & 0.49 & & & & & & & & & \\
\hline 2. Age & 2.91 & 0.81 & $0.22^{* * *}$ & & & & & & & & \\
\hline 3. Job category & 0.32 & 0.47 & 0.08 & 0.10 & & & & & & & \\
\hline 4. Employment status & 0.78 & 0.42 & 0.06 & $0.23^{* * *}$ & $-0.16^{* *}$ & & & & & & \\
\hline 5. Work type & 0.76 & 0.43 & 0.09 & 0.03 & -0.09 & 0.37 & & & & & \\
\hline 6. Organizational tenure & 2.66 & 1.02 & 0.08 & $0.41^{* * *}$ & -0.08 & $0.32^{2}$ & 80 & & & & \\
\hline 7. Organizational inclusion & 2.97 & 0.85 & -0.06 & -0.00 & -0.03 & -0.07 & 0.04 & -0.10 & & & \\
\hline 8. Distributive justice & 3.11 & 1.09 & -0.07 & $-0.15^{*}$ & $-0.13^{*}$ & -0.05 & -0.02 & -0.06 & $0.48^{* * *}$ & & \\
\hline 9. Procedural justice & 3.16 & 0.70 & -0.03 & -0.10 & $-0.19^{* *}$ & -0.08 & -0.07 & -0.08 & $0.52^{* * *}$ & $0.60^{* * *}$ & \\
\hline 10. Affective wellbeing & 2.93 & 0.98 & -0.20 & -0.09 & $-0.12^{+}$ & -0.10 & -0.09 & -0.07 & $0.34^{* * *}$ & $0.48^{* * *}$ & $0.43^{* * *}$ \\
\hline
\end{tabular}

Note: $\mathrm{N}=253 .{ }^{* * *} p<0.001,{ }^{* *} p<0.01,{ }^{*} p<0.05,{ }^{+} p<0.10$. 
Table 3. Fit indexes for competing structural models

\begin{tabular}{lcc}
\hline Fit indexes & Full mediation model & Partial mediation model \\
\hline$\chi^{2}$ & 135.11 & 134.00 \\
$d f$ & 97 & 96 \\
$\chi^{2} / d f$ & 1.39 & 1.40 \\
SRMR & 0.03 & 0.03 \\
RMSEA & 0.04 & 0.04 \\
CFI & 0.98 & 0.98 \\
AIC & 283.11 & 284.00 \\
ECVI & 1.12 & 1.13 \\
\hline
\end{tabular}

Note: $\mathrm{N}=253$. Full mediation model has two indirect paths: organizational inclusion $\rightarrow$ distributive justice $\rightarrow$ affective wellbeing, and organizational inclusion $\rightarrow$ procedural justice $\rightarrow$ affective wellbeing. The partial mediation model adds the direct path from organizational inclusion to affective wellbeing to the full mediation model. 


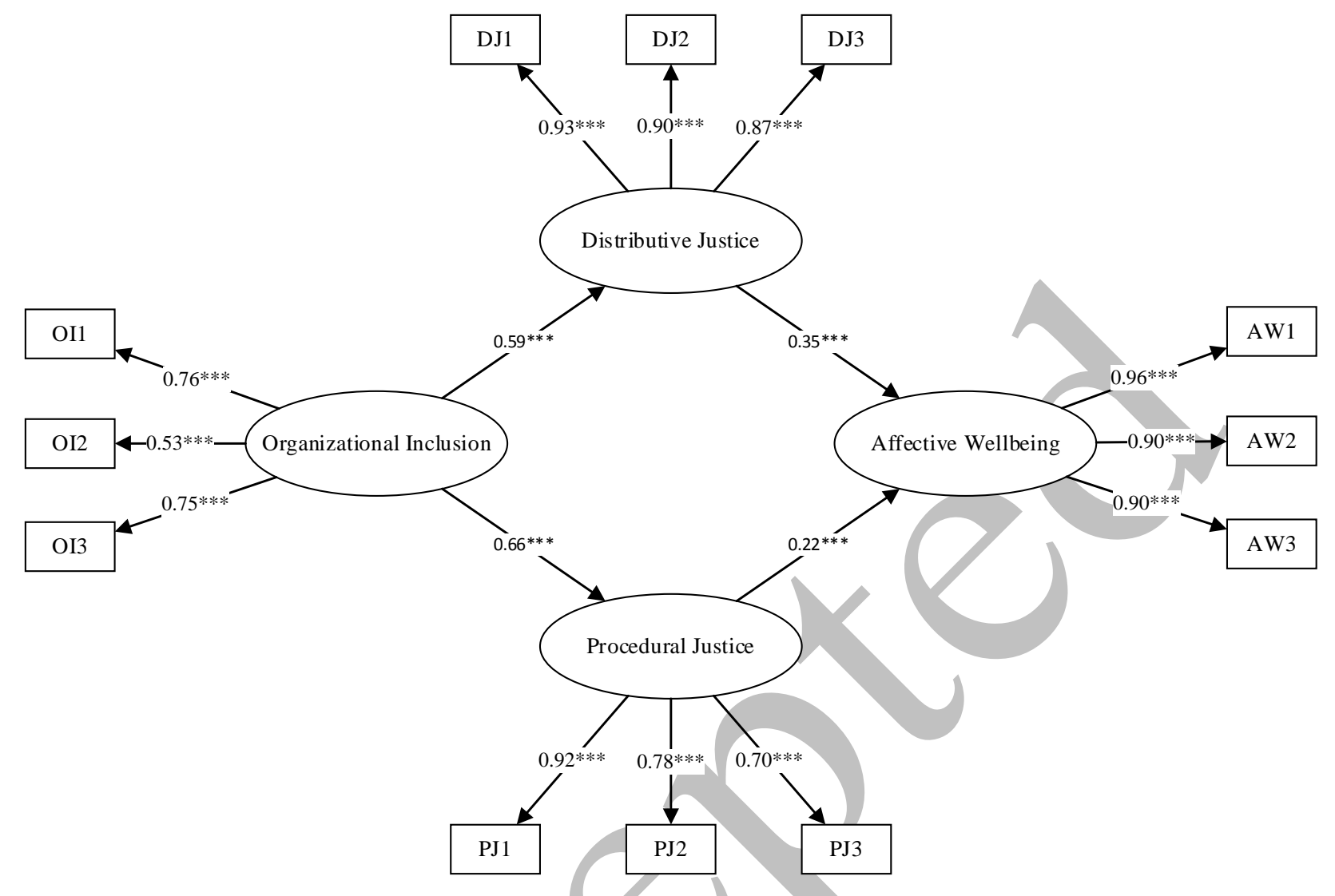

Fig. 1. The final structural model. Note: Standardized estimates are reported. Gender, age, job category, employment status, work type, and organizational tenure were controlled. ${ }^{* * *} \mathrm{p}<.001$. 